\title{
Neutronic Analysis of LEU-started Molten Chloride Fast Reactor without Fuel Reprocessing
}

\author{
R. Andika Putra Dwijayanto ${ }^{1,2, a}$ and Andang Widi Harto ${ }^{1}$ \\ ${ }^{1}$ Department of Nuclear Engineering and Physics Engineering, Universitas Gadjah Mada, \\ JI. Grafika No. 2, Yogyakarta, Indonesia 55281 \\ ${ }^{2}$ Centre for Nuclear Reactor Technology and Safety, National Nuclear Energy Agency, Building \\ No. 80 Puspiptek Area, South Tangerang, Indonesia 15310 \\ aputra-dwijayanto@batan.go.id
}

\begin{abstract}
One of the rarely explored Molten Salt Reactor (MSR) designs is the Molten Chloride Fast Reactor (MCFR). This MSR design employs chloride salt instead of fluoride and operated in a fast spectrum. MCFR brings all the advantages of an MSR including breeding whilst being able to burn plutonium and minor actinides efficiently. Since not many countries have access to civilian plutonium, MCFR can also be started using Low-enriched Uranium (LEU). This study is an initial neutronic analysis of an MCFR using LEU as its startup fuel. Parameters analyzed are Conversion Ratio (CR) and its neutronic safety, namely effective delayed neutron fraction $\left(\beta_{\text {eff }}\right)$, Temperature Coefficient of Reactivity (TCR), and Void Coefficient of Reactivity (VCR). The core is divided into Core Zone and Blanket Zone. The fuel composition of $\mathrm{NaCl}-\mathrm{UCl}_{3}$ with a molar fraction ratio of 60:40 and 50:50 is used in Core Zone and Blanket Zone, respectively. The neutronic calculation is performed using MCNP6 code with ENDF/B-VII library. For reference geometry, CR is valued at $0.9298, \beta_{\text {eff }}$ at 0.00731 , TCR at $-19.8 \mathrm{pcm} /{ }^{\circ} \mathrm{C}$, and average VCR at $-154.31 \mathrm{pcm} / \mathrm{void} \%$. Thereby, the MCFR fulfills inherent safety criteria. Although its value is remarkably high, $\mathrm{CR}$ can be further optimized by modifying the separator and reflector material.
\end{abstract}

Keywords: MCFR, Conversion Ratio, Effectively Delayed Neutron Fraction, Temperature Coefficient of Reactivity, Void Coefficient of Reactivity

\section{Introduction}

Molten Salt Reactor (MSR) is a general term for any reactor that uses liquid fuel in a salt-bound compound. Fissile and fertile fuel, either uranium, thorium, or plutonium, is dissolved within a molten carrier salt such as fluoride salt and chloride salt. The liquid fuel acts both as fuel and coolant, and the fuel is circulating the primary system instead of static [1-3].

As a liquid-fuelled reactor, MSR offers many advantages compared to conventional light water reactors. Among them are [1-5],

- Atmospheric operational pressure due to high boiling point of salt, eliminating the need of pressure vessel.

- Operability in high temperature $\left(700^{\circ} \mathrm{C}\right.$ and higher).

- High coefficient of thermal expansion, which provides negative temperature reactivity coefficient.

- No possibility of hydrogen explosion due to the absence of water in the primary loop.

- No fuel fabrication is required, which drives down fuel cost and increasing neutron economy due to lower parasitic capture. 
- Salt is highly radiation damage-resistant, thus allowing the fuel to stay indefinitely in the core and attaining high burnup.

- Possible online fuel reprocessing to remove fission products and actinides, allowing thermal breeding for MSR utilizing thorium fuel cycle.

MSR is offered in various designs; moderated [4,6-10] or unmoderated [11-16], fluoride or chloride, thorium or uranium. Most MSR researches and designs favor thermal MSR, leaving only a handful of designs of fast MSRs, such as French MSFR [11], TerraPower's MCFR [17], and Elysium Industries' MCSFR [18]. Whilst MSFR is intensively researched, little to no details surrounding the latter two. Coincidentally, those obscure designs are categorized into molten chloride fast reactors (MCFRs).

Among possible MSR designs, MCFR is one of the least explored. It employs chloride salt instead of fluoride salt $[19,20]$. Chloride provides a harder neutron spectrum, and thus more suitable for Uranium-Plutonium (U-Pu) cycle [21]. Chloride salt can dissolve a higher fraction of plutonium and Minor Actinide (MA) compared to fluoride salt [15,22,23]. MCFR runs with sodium chloride as its coolant, avoiding the requirement of highly enriched lithium-7 in fluoride salt. Researches in MSFR show that fast MSR requires less fuel processing thanks to higher neutron economy [11], and MCFR is likely to show similar characteristic.

Those aforementioned characteristics make MCFR an interesting design for uranium utilization and MA burning. MCFR can be used to incinerate both military and civilian plutonium along with MA whilst being self-sustaining. For countries with no access to plutonium, MCFR can be started using LEU and gradually transition into equilibrium U-Pu core. Owing to its excellent neutron economy, the U-Pu MCFR core is potentially suitable to breed U-233 from thorium on its blanket. Despite the features, it offers, researches regarding MCFR is quite scarce. Thus, MCFR performance is barely understood, including the extent of its safety characteristics.

This research is performed as an initial study on the neutronic performance of an MCFR started with LEU. The fuel is chosen as it is the most widely available fissile fuel, and thus more likely to be used in countries that own no Pu. As an initial study, the parameters calculated are conversion ratio $(\mathrm{CR})$ along with neutronic safety parameters such as effectively delayed neutron fraction $\left(\beta_{\text {eff }}\right)$, Temperature Coefficient of Reactivity (TCR), and Void Coefficient of Reactivity (VCR). The calculation is performed using MCNP6 radiation transport code with ENDF/B-VII continuous neutron library.

\section{General Description}

Most MCFR designs opted for cylindrical core [17-20,23]. At the time this paper is written, it is unknown whether Elysium Industries' MCSFR employs a single zone or dual zone, whilst limited data regarding TerraPower's shows that it employs a single zone [17]. MCFR assessed in SINAP uses dual-zone, separating the fissile and fertile zone [23]. Stable Salt Reactor (SSR), another design using chloride salt, is a static-fuelled MSR with separate fuel and coolant salt $[15,22]$. MCFR design in this study was adapted from REBUS [21], and thereby separate Core and Blanket Zone are used. This configuration is similarly used by Chinese MCFR.

The Core Zone is a hollow cylinder surrounded by a Blanket Zone; each zone is separated by a separator material. The diameter and height of the core are equal. The fluid fuel enters the Core 
Zone from the bottom, heated by fission inside the core, and exits the core at the top. The heat is then transferred to the secondary salt loop before the cooled salt re-enters the core. Fertileonly Blanket Zone surrounds the core with a thickness of $50 \mathrm{~cm}$ on the radial region and $25 \mathrm{~cm}$ on the axial regions. The Core and Blanket are separated by a $10-\mathrm{cm}$ thick separator. Reflector material is placed surrounding both Core and Blanket Zones, and further enclosed by stainless steel core shroud. Understanding the harsh nature of a fast reactor, the whole core components are not expected to last for dozens of years but are designed to be easily replaced after a few years of operation. The graphical design of MCFR core is provided in Figure 1.

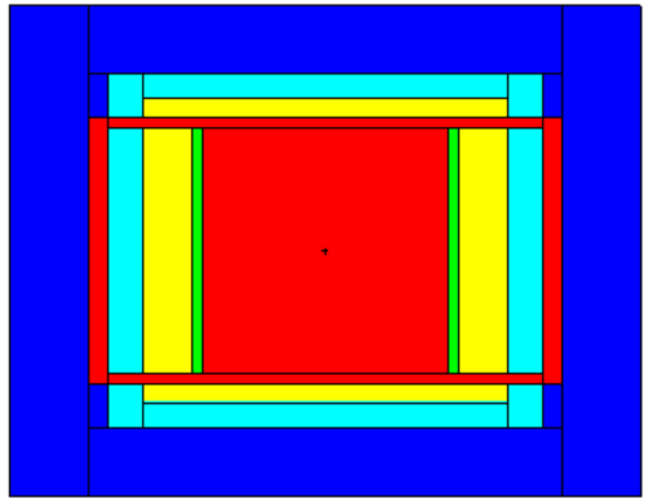

(a)

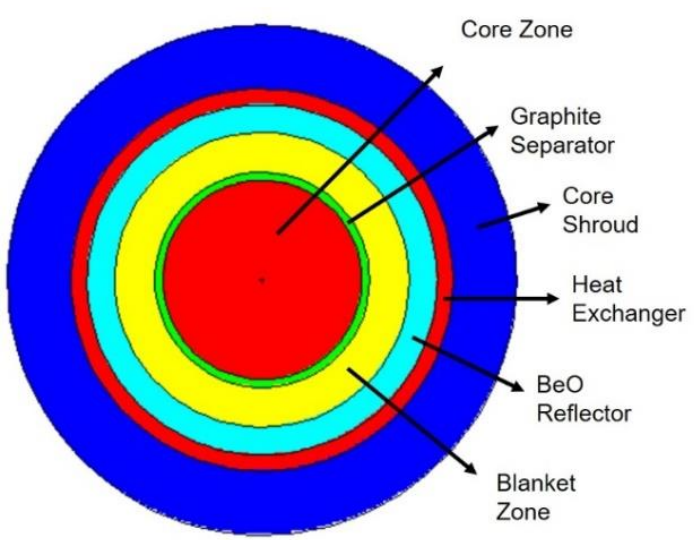

(b)

Figure 1. MCNP model of MCFR core (a) axial view, (b) radial view

The most distinctive difference between MCFR and thermal MSR is the utilization of chloride salt instead of fluoride. Chloride is a poor neutron moderator compared to fluoride and thereby provides a harder spectrum. It benefits the most in U-Pu cycle, which allows a higher neutron economy and better breeding capability. As carrier salt, $\mathrm{NaCl}$ is used in place of LiF. To optimize breeding, Cl-37 isotope is enriched to $99.95 \%$. This way, parasitic absorption by $\mathrm{Cl}-35$, which proves to be obstructing the neutron economy and resulting in long-lived radioactive waste [23], can be minimized.

Chloride salt can dissolve a higher amount of actinide compared to fluoride salt. In this study, a $\mathrm{NaCl}-\mathrm{UCl}_{3}$ mixture with the molar proportion of $60 \%-40 \%$ for Core Zone and $50 \%-50 \%$ for Blanket Zone. Low-enriched Uranium (LEU) is used in Core Zone, with the enrichment level is set below $20 \%$ limit to minimize fissile load whilst allowing higher fertile load, to enhance breeding. Higher fertile load in Blanket Zone is similarly intended to increase fissile breeding. Uranium used in Blanket Zone has depleted uranium with $0.2 w t \%$ of fissile U-235.

MCFR parameters used in this study are shown in Table 1.

Table 1. MCFR Core Parameters

\begin{tabular}{lc}
\hline \multicolumn{1}{c}{ Parameters } & Value \\
\hline Thermal power $(\mathrm{MWt})$ & 3000 \\
Power density $\left(\mathrm{MWt} / \mathrm{m}^{3}\right)$ & 244 \\
Core diameter $(\mathrm{cm})$ & 250 \\
Core height $(\mathrm{cm})$ & 250 \\
Fuel salt composition (mol\%) & $60 \mathrm{NaCl}-40$ (low-enriched) $\mathrm{UCl}_{3}$
\end{tabular}




\begin{tabular}{lc}
\hline \multicolumn{1}{c}{ Parameters } & Value \\
\hline Fertile salt composition $(\mathrm{mol} \%)$ & $50 \mathrm{NaCl}-50$ (depleted) $\mathrm{UCl}_{3}$ \\
Salt temperature $\left({ }^{\circ} \mathrm{C}\right)$ & 630 \\
Fuel salt density $\left(\mathrm{g} / \mathrm{cm}^{3}\right)$ & 4.22 \\
Fertile salt density $\left(\mathrm{g} / \mathrm{cm}^{3}\right)$ & 4.71 \\
Separator material & Graphite \\
Separator density $\left(\mathrm{g} / \mathrm{cm}^{3}\right)$ & 1.85 \\
Reflector material & BeO \\
Reflector density $\left(\mathrm{g} / \mathrm{cm}^{3}\right)$ & 3.01 \\
Core shroud material & Stainless Steel \\
Core shroud density $\left(\mathrm{g} / \mathrm{cm}^{3}\right)$ & 7.98 \\
\hline
\end{tabular}

\section{Materials and Methods}

MCFR benefits from a hard neutron spectrum and better neutron economy, so the influence of neutron-absorbing Fission Products (FPs) such as Xe-135 and Sm-149 is much less affecting reactor operation. The requirement of online reprocessing is also much smaller. In MSFR, reprocessing is performed only for 40 liters/day, compared to $4.6 \mathrm{~m}_{3} /$ day for MSBR [11,24]. Nevertheless, this study assumes batch reprocessing, considering that it is comparably simpler than online fuel reprocessing, and neutron economy requirement in U-Pu cycle is less stringent than that of U-Th cycle. The fuel is burned inside the core for a whole year, then the FPs are extracted and fissile fuel bred from Blanket Zone is added into the core along with new fertile fuel.

The calculation is performed using Monte Carlo N-Particle version 6 (MCNP6) with ENDF/B-VII continuous neutron group library. KCODE module is employed to calculate criticality. Neutrons simulated per $k_{\text {eff }}$ cycle are set at 10,000 for a total of 250 cycles, with the first 50 cycles are discarded.

Since this study omits online fuel reprocessing, sufficient excess reactivity is required to maintain criticality for each cycle, in this case, one year. Various fuel enrichment levels will be assessed, but only those with $k_{\text {eff }}$ slightly above unity are considered for burnup calculation. This is to keep excess reactivity as low as possible, to maintain reactor control with minimum reactivity control mechanism requirement.

$\beta_{\text {eff }}$ value is calculated in MCNP6 using KOPTS card [25]. One distinguishing difference between MSR and the conventional reactor is that MSR fuel is constantly circulating. Consequently, some fraction of $\beta_{\text {eff }}$ is "lost" from the core $[26,27]$. The real $\beta_{\text {eff }}$ value is lower from the value calculated by MCNP, which can range from $10 \%$ in MSR-FUJI to $40 \%$ in MSBR case [28]. Calculation of lost $\beta_{\text {eff }}$ is beyond the scope of this study so that the $\beta_{\text {eff }}$ value calculated is left as it is.

TCR is calculated by varying the operational temperature from its operational temperature. Criticality calculation is employed in temperatures of $600 \mathrm{~K}, 900 \mathrm{~K}$, and $1200 \mathrm{~K}$. Due to thermal expansion, fuel density is different for each temperature, and therefore adjusted accordingly. In MSR system, fuel density change can be treated as void. Thus, VCR in MCFR is calculated by lowering the density of fuel salt both in Core Zone and Blanket Zone. The density change is calculated for a void fraction of $0-50 \%$. 
MCFR started with LEU is unable to breed. Nevertheless, to minimize fissile fuel consumption and reducing the additional fissile requirement for the next cycle, the conversion ratio (CR) must be achieved as high as possible. CR value in this study is defined by the following equation.

$C R=\frac{\sum \text { fissile gain }_{\text {core }}+\sum \text { fissile gain }_{\text {blanket }}}{U_{235} \text { lost }}$

Burn-up calculation is performed by employing a built-in CINDER90 depletion code. The irradiation time is set as 365 days with nominal power of $3000 \mathrm{MWt}$.

\section{Results and Discussion}

LEU-started MCFR can be critical with minimum U-235 enrichment of $13.7 \mathrm{wt} \%$. Usually, MSR is kept critical with low excess reactivity, with $k_{\text {eff }}$ below $1+\beta$. MCFR employs batch reprocessing and batch refueling, thus higher excess reactivity is necessary. Fuel enrichment is then varied at $13.7 w t \%, 13.75 w t \%$, and $13.8 w t \%$. The enrichment increase is not necessarily large since fast reactor is relatively more sensitive to fissile change in the reactor.

The $k_{\text {eff }}$ value at Beginning of Cycle (BOC) and End of a Cycle (EOC) with various fuel enrichment is presented in Table 2.

Table 2. $k_{\text {eff }}$ of MCFR at BOC and EOC

\begin{tabular}{cccc}
\hline \multirow{2}{*}{ Fuel enrichment } & \multicolumn{2}{c}{$\mathbf{k}_{\text {eff }}$} & $\begin{array}{c}\text { Reactivity Swing } \\
\text { (pcm) }\end{array}$ \\
\cline { 2 - 4 } & BOC & EOC & 470.38 \\
$13.7 w t \%$ & $1.00621 \pm 0.00036$ & $1.00147 \pm 0.00036$ & 560.43 \\
$13.75 w t \%$ & $1.00779 \pm 0.00039$ & $1.00213 \pm 0.00036$ & 576.61 \\
$13.8 w t \%$ & $1.00931 \pm 0.00039$ & $1.00347 \pm 0.00036$ & \\
\hline
\end{tabular}

It can be understood that fuel enrichment of $13.7 \mathrm{wt} \%$ is sufficient to maintain criticality for one year. The value is satisfying in two terms. The first being a low reactivity swing, amounting of $470 \mathrm{pcm}$. Part of the reason is the high conversion rate, which allows the reactor to stay critical for a longer time with minimum excess reactivity. Higher enrichment resulted in higher reactivity swing, due to lower breeding or in situ consumption of Pu-239 bred in the core. The second is

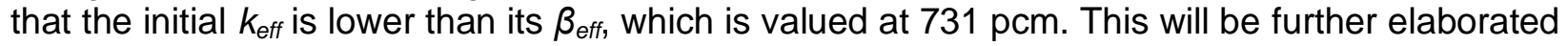
on later.

CR value for each enrichment is calculated using Equation 1. Pu-239, Pu-241 and Np-239 are all calculated for CR. The latter is included since it will eventually beta-decay into Pu-239. The mass balance of heavy metal at BOC and EOC is given in Table 3.

Table 3. Mass balance of heavy metal and conversion ratio

\begin{tabular}{|c|c|c|c|c|c|c|}
\hline \multirow[b]{2}{*}{ Nuclide } & \multicolumn{2}{|c|}{$13.7 w t \%$} & \multicolumn{2}{|c|}{$13.75 w t \%$} & \multicolumn{2}{|c|}{$13.8 w t \%$} \\
\hline & $\begin{array}{l}\text { Mass at } \\
\text { BOC (kg) }\end{array}$ & $\begin{array}{l}\text { Mass at } \\
\text { EOC }(\mathrm{kg})\end{array}$ & $\begin{array}{l}\text { Mass at } \\
\text { BOC }(\mathrm{kg})\end{array}$ & $\begin{array}{l}\text { Mass at } \\
\text { EOC }(\mathrm{kg})\end{array}$ & $\begin{array}{l}\text { Mass at } \\
\text { BOC }(\mathrm{kg})\end{array}$ & $\begin{array}{l}\text { Mass at } \\
\text { EOC (kg) }\end{array}$ \\
\hline $\begin{array}{l}\text { U-235 } \\
\text { Pu-239 }\end{array}$ & $7,169.00$ & $6,038.00$ & $7,195.00$ & $6,065.00$ & $7,221.00$ & $6,089.00$ \\
\hline Core & - & 659.70 & & 656.70 & & 656.60 \\
\hline Blanket & - & 374.30 & & 374.20 & & 373.20 \\
\hline
\end{tabular}




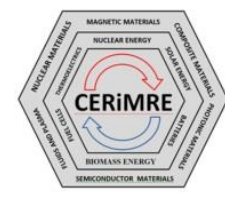

\begin{tabular}{|c|c|c|c|c|c|c|}
\hline \multirow[b]{2}{*}{ Nuclide } & \multicolumn{2}{|c|}{$13.7 w t \%$} & \multicolumn{2}{|c|}{$13.75 w t \%$} & \multicolumn{2}{|c|}{$13.8 w t \%$} \\
\hline & $\begin{array}{c}\text { Mass at } \\
\text { BOC }(\mathrm{kg})\end{array}$ & $\begin{array}{c}\text { Mass at } \\
\text { EOC }(\mathrm{kg})\end{array}$ & $\begin{array}{c}\text { Mass at } \\
\text { BOC (kg) }\end{array}$ & $\begin{array}{c}\text { Mass at } \\
\text { EOC }(\mathrm{kg})\end{array}$ & $\begin{array}{c}\text { Mass at } \\
\text { BOC }(\mathrm{kg})\end{array}$ & $\begin{array}{l}\text { Mass at } \\
\text { EOC (kg) }\end{array}$ \\
\hline \multicolumn{7}{|l|}{ Pu-241 } \\
\hline Core & - & 0.79 & & 0.81 & & 0.79 \\
\hline $\begin{array}{l}\text { Blanket } \\
\text { Np-239 }\end{array}$ & - & 5.60 & & 5.54 & & 5.57 \\
\hline Core & - & 6.73 & & 6.70 & & 6.70 \\
\hline Blanket & - & 4.42 & & 4.42 & & 4.40 \\
\hline Fissile lost & $1,131.00$ & & $1,130.00$ & & $1,132.00$ & \\
\hline $\begin{array}{c}\text { Fissile gain } \\
\text { CR }\end{array}$ & 0.5 & $\begin{array}{l}1,051.55 \\
98 \\
\end{array}$ & 0. & $\begin{array}{l}1,048.37 \\
78\end{array}$ & 0.5 & $\begin{array}{l}1,047.25 \\
51\end{array}$ \\
\hline
\end{tabular}

The maximum CR obtained is 0.9298 . Such value is remarkably high, knowing that the reactor is fuelled by U-235. About two-third of the plutonium is formed in Fuel Zone, with the rest formed in Blanket Zone. The high fertile fraction in Blanket Zone helped to enhance fissile breeding.

Since the CR is below unity, the reactor itself cannot be defined as a breeder. However, plutonium bred from Blanket Zone is supposed to be sufficient to self-sustain the MCFR without the addition of external $U-235$. This is due to the fact that plutonium performs better in fast spectrum than U-235, and thus reducing core critical mass.

Highly enriched $\mathrm{Cl}-37$ also helped in increasing CR. Unenriched $\mathrm{Cl}-37$ has been proven to hinder the neutronic performance of MCFR, contributed by parasitic neutron capture by predominant $\mathrm{Cl}-35$. Apart from reducing neutronic performance, high $\mathrm{Cl}-35$ content also resulted in large activation product $\mathrm{Cl}-36$, a long-lived radionuclide, as the waste. as well as corrosive sulfur. Therefore, $\mathrm{Cl}-37$ enrichment is recommended in MCFR.

Neutron spectrum analysis is done only for $13.7 \mathrm{wt} \%$ fuel enrichment. After irradiation, the neutron spectrum in Core Zone does not shift significantly. Only slight softening is observed, as the fission products build up whilst $\mathrm{Pu}-239$ is yet to be the dominant fissile isotope. In BOC, only around $8.74 \%$ of fission event occurs at thermal spectrum. The rest of fission occurs in the intermediate and fast spectrum, with approximately equal share. At EOC, thermal fission share increased to around $12.76 \%$, reducing the intermediate and fast fission, thereby the spectrum softening. The neutron spectrum is displayed in Figure 2. 


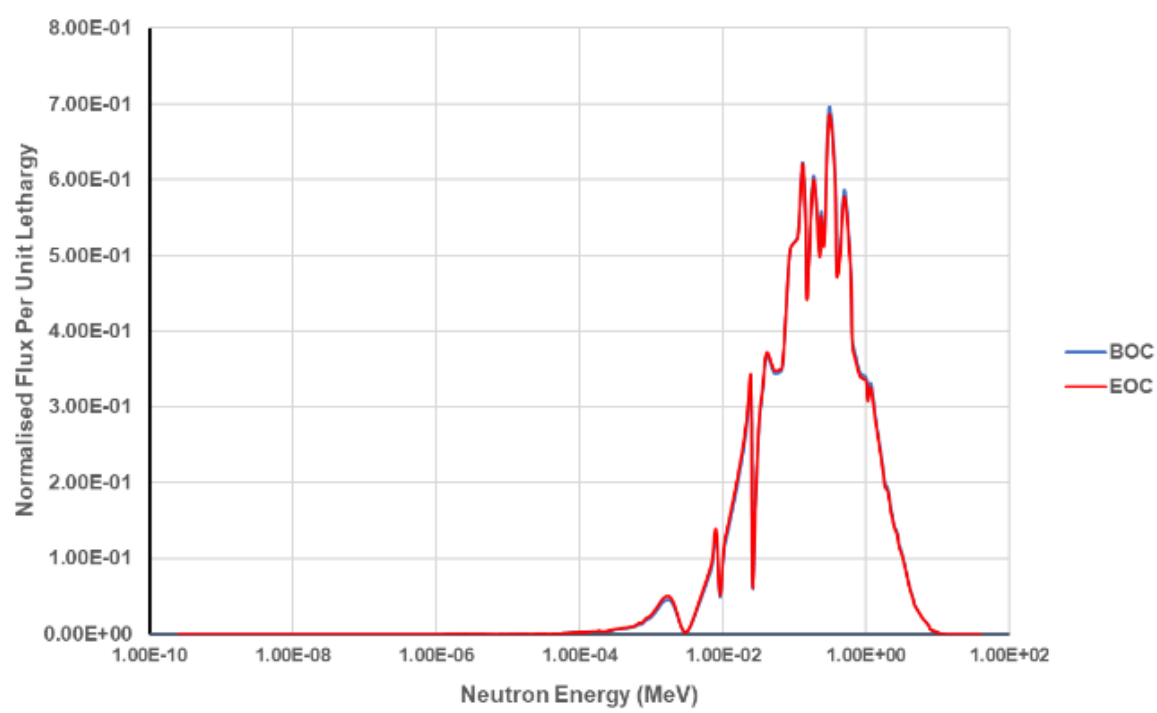

(a)

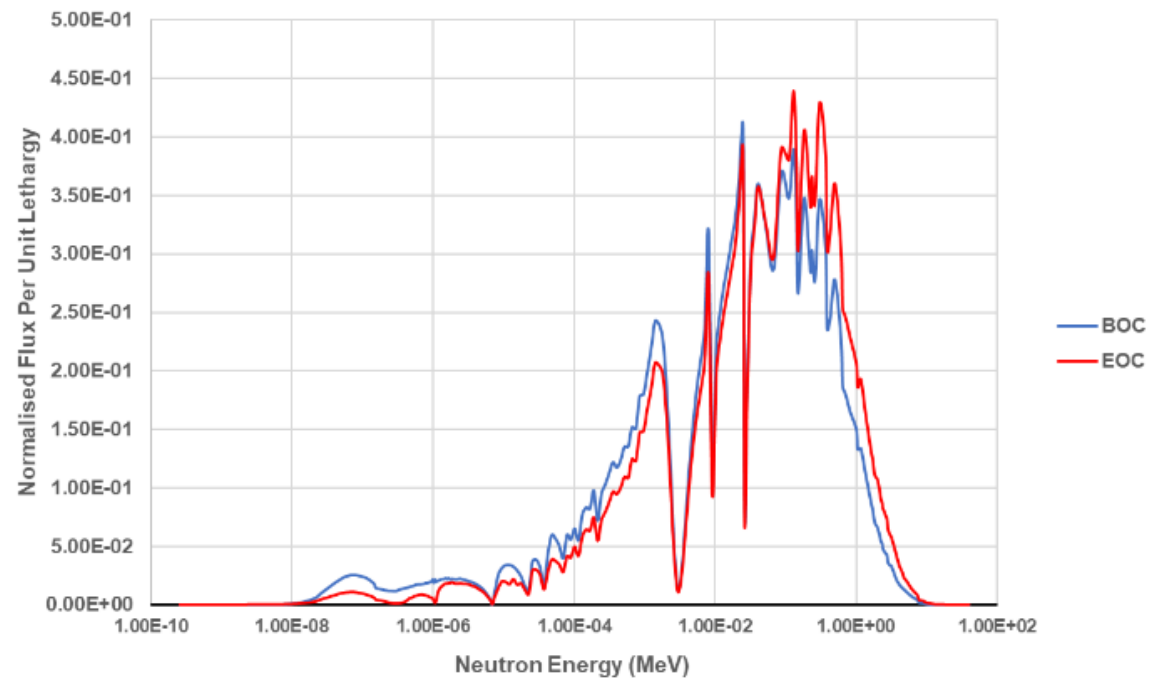

(b)

Figure 2. Neutron spectrum of MCFR (a) Core Zone and (b) Blanket Zone

Using graphite as separator material reduced neutron energy when it enters Blanket Zone. This caused the spectrum to be softened compared to Core Zone, with the highest flux is considerably lower and located in the lower neutron energy zone. BeO reflector may also induce neutron moderation, but its extent is currently unknown. From this finding, it can be concluded that using different separator and reflector material may result in different neutron spectrums, either hardening or softening, thereby affecting CR. Thus, CR value can be further optimized by exploring the options of separator and reflector material.

The next calculation is on neutronic safety. The calculation was performed only for MCFR core with LEU enrichment of $13.7 \mathrm{wt} \%$. Among the important neutronic safety, parameters are delayed effective neutron fraction $\left(\beta_{\text {eff }}\right)$, temperature coefficient of reactivity (TCR), and void coefficient of reactivity (VCR). $\beta_{\text {eff }}$ is an influential factor in determining reactor controllability. 
Low $\beta_{\text {eff }}$ usually necessitates tighter reactivity control, since the reactor period is shortened and the margin to prompt criticality is smaller. This is especially a challenge in a breeder reactor, since fissile Pu-239 and U-233, the only two isotopes that are suitable for breeding, possess lower $\beta_{\text {eff }}$ than U-235 usually used in conventional reactors.

$\beta_{\text {eff }}$ value shifts as the fissile U-235 is burnt and Pu-239 is formed both in the Core Zone and Blanket Zone. The value at the BOC and EOC is shown in Table 2.

Table 2. $\beta_{\text {eff }}$ value at BOC and EOC

\begin{tabular}{lc}
\hline \multicolumn{1}{c}{ Condition } & $\boldsymbol{\beta}_{\text {eff }}$ \\
\hline BOC & $0.00731 \pm 0.00072$ \\
EOC & $0.00617 \pm 0.00064$ \\
\hline
\end{tabular}

At the $\mathrm{BOC}, \beta_{\text {eff }}$ value is higher than $\beta$ value of $U-235$, whilst at the $E O C, \beta_{\text {eff }}$ value is only slightly lower than $650 \mathrm{pcm}$. The values are expected as Pu-239 is forming in both zones, reducing delayed neutron fraction. During the subsequent cycles, $\beta_{\text {eff }}$ should be decreased even more.

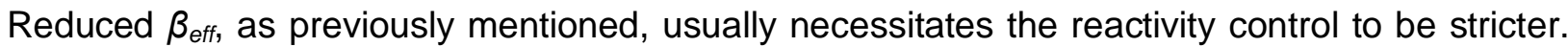
In this case, however, reactivity control can somehow be compensated by Pu-239 addition into the Core Zone. This is due to Pu-239 is significantly better than U-235 in the fast spectrum, so that criticality can be maintained even longer with lower excess reactivity.

It must be understood that the $\beta_{\text {eff }}$ calculated in this study ignores the $\beta_{\text {eff }}$ fraction lost due to fuel circulation. Calculating lost $\beta_{\text {eff }}$ must consider the fuel flow rate, which is beyond the scope of this study. Fuel circulating time in the primary loop is usually less than a minute, thus some groups of delayed neutrons can also be generated when the fuel is returned into the core. Therefore, even though the $k_{\text {eff }}$ value of $13.7 \mathrm{wt} \%$ enrichment is below $\beta_{\text {eff, }}$ as mentioned in the previous subsection, the real $\beta_{\text {eff }}$ may not necessarily above the $k_{\text {eff. }}$ This will be addressed in future works.

Temperature Coefficient of Reactivity (TCR) is defined as reactivity change due to temperature change of core component. In any reactor, TCR must be kept negative. Whilst thermal MSR somehow suffers from the positive temperature feedback from graphite moderators, fast MSR does not incur the same issue. In thermal reactors, TCR usually comprises of Fuel Coefficient of Temperature (FCT) and Moderator Coefficient of Temperature (MCT). Since fast reactor omits moderator from the system, TCR in MCFR only considers FCT. The latter consists of the fuel density coefficient and Doppler coefficient.

Temperature simulated in this study is $600 \mathrm{~K}, 900 \mathrm{~K}$ and $1200 \mathrm{~K}$. Molten salt expands when heated, lowering its density. Thus, fuel density is corrected for a given temperature. Fuel density correction is applied for both Core Zone and radial Blanket Zone. Meanwhile, fuel density outside Core Zone and axial Blanket Zone are kept constant. The rationale is that fuel expansion due to heating occurs mainly in Core Zone and adjacent Blanket Zone. The temperature of non-fuel materials is adjusted accordingly. As a comparison, the calculation was also performed for fuel density adjustment in Core Zone only. Using the above assumptions, TCR value of MCFR at BOC is indicated in Figure 3. 


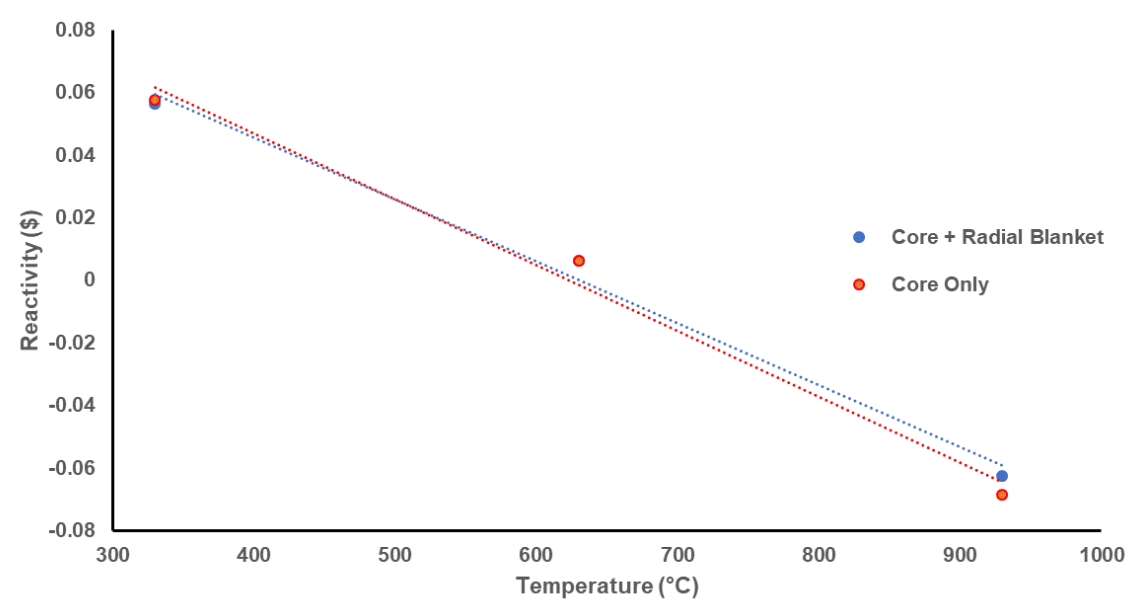

Figure 3. TCR of MCFR at BOC

For density adjustment in Core and radial Blanket, TCR is calculated at $-19.8 \mathrm{pcm} / \mathrm{K}$, whilst when density adjustment in core only resulted in TCR of $-21 \mathrm{pcm} / \mathrm{K}$. A difference of $1.2 \mathrm{pcm} / \mathrm{K}$ is shown when fuel density in Blanket Zone is considered, which is insignificant compared to the absolute TCR value. Nevertheless, it was seen that blanket expansion resulted in lower negative reactivity. This is due to lower neutron capture by the blanket, as depleted uranium is pushed out of the radial Blanket Zone when the fuel expands.

Either value is comparably more negative compared to other fast MSR designs, including Chinese MCFR. When compared to fluoride MSFR, more negative TCR is induced by higher thermal expansion of chloride salt. Thus, given the same temperature increase, chloride fuel expands larger than its fluoride counterpart, and thereby its fuel density is reduced even larger.

Meanwhile, compared to Chinese MCFR, more negative TCR may be induced by different fuel cycles (U-Pu for MCFR and U-Th for Chinese MCFR) or different core size. MCFR core diameter and height in this study are only half of that Chinese MCFR dimension. The smaller core size of MCFR makes it more sensitive to fuel density change since more fissile will be pushed out of the core, further exacerbated by the high thermal expansion of chloride salt.

The MCFR design satisfies inherent safety criteria. However, the extremely negative TCR necessitates more assessment of its reactivity control.

In MSR, the salt density coefficient can be treated as VCR. Whilst thermal MSR may incur a positive void coefficient if the core is under-moderated, fast MSR does not face the same issue. In MCFR, VCR is calculated by reducing fuel density both in Core Zone and Blanket Zone. The assumption is similar with TCR, fuel density is corrected only in Core Zone and radial Blanket Zone, with other calculation with density correction in Core Zone only is performed as a comparison. $k_{\text {eff }}$ change against void fraction is shown in Figure 4. 


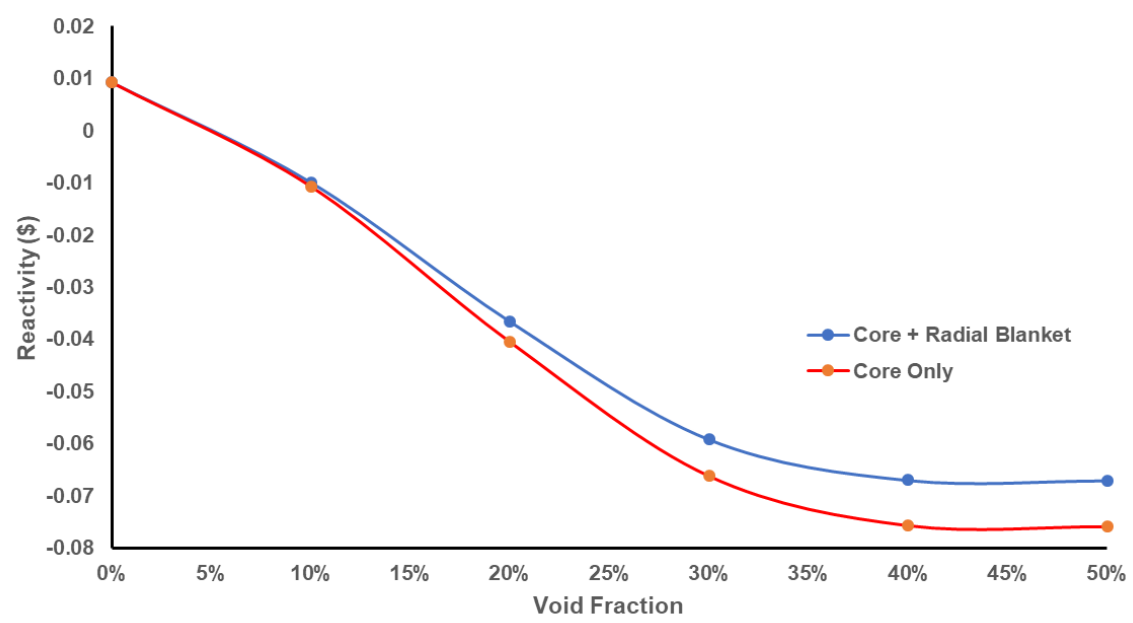

Figure 4. VCR of MCFR at BOC with different salt density correction

In both calculations, criticality change against the void is not linear. Reactivity decreased the steepest from a void fraction $10 \%$ to $20 \%$. However, from the void fraction of $40 \%$ to $50 \%$, reactivity only decreased for less than $5 \mathrm{pcm}$ for density reduction in core only. Strangely, for density reduction in Core and radial Blanket, at the same void increase, the $k_{\text {eff }}$ is increasing instead of decreasing.

The average VCR is calculated at $-176.59 \mathrm{pcm} /$ void\% for density reduction in Core Zone and $154.31 \mathrm{pcm} /$ void\% for density reduction in Core Zone + radial Blanket Zone. From those values, blanket salt expansion is proven to be lowering the negative reactivity, since density reduction means that lower fertile salt capture neutrons. Thus, blanket salt expansion induced positive void reactivity, although not particularly significant compared to core salt expansion.

Both values are extremely negative and ensure that inherent safety is achieved. Although, compared to MSFR design, the difference in VCR value is significant. Thermal expansion of chloride salt might play a part in this difference. To provide a better perspective, VCR for each step of void fraction change is given in Table 3.

Table 3. VCR at each step of void change

\begin{tabular}{ccc}
\hline $\begin{array}{c}\text { Salt Density } \\
\text { Correction }\end{array}$ & Core Only & $\begin{array}{c}\text { Core + Radial } \\
\text { Blanket }\end{array}$ \\
\hline Void Change & $\begin{array}{c}\text { VCR for given void } \\
\text { change (pcm) }\end{array}$ & $\begin{array}{c}\text { VCR for given void } \\
\text { change (pcm) }\end{array}$ \\
\hline $0-10 \%$ & -257.89 & -260.39 \\
$10-20 \%$ & -310.34 & -265.30 \\
$20-30 \%$ & -238.66 & -206.79 \\
$30-40 \%$ & -71.25 & -56.43 \\
$40-50 \%$ & -4.80 & 17.35 \\
\hline Average & -176.59 & -154.31 \\
\hline
\end{tabular}




\section{Conclusions}

An analysis of neutronic performance and safety on an MCFR showed encouraging results. For a fast reactor started with LEU, achieving CR value at 0.9298 is remarkable. Especially considering that MCFR ignores gaseous fission product removal and online fuel reprocessing altogether. For the next cycle, external fissile addition is unnecessary as critical mass is reduced and lower excess reactivity is required. MCFR design employed in this study fulfills inherent safety criteria. Both TCR and VCR are sufficiently negative, although their highly negative value must be taken into consideration for reactivity control. $\beta_{\text {eff }}$ lowering after a year may reduce reactor controllability and must be considered for its reactivity control system since fuel makeup in MCFR is annually instead of daily.

\section{ACKNOWLEDGEMENTS}

The work presented in this paper was supported by the research budget of the Centre for Nuclear Reactor Technology and Safety, National Nuclear Energy Agency, the fiscal year 2020.

\section{References}

[1] D. LeBlanc, 2010, Molten salt reactors: A new beginning for an old idea, Nucl. Eng. Des., volume 240 , no. 6 , page 1644-1656.

[2] J. Serp et al., 2014, The molten salt reactor (MSR) in Generation IV: Overview and perspectives, Prog. Nucl. Energy, volume 77, page 308-319.

[3] J. Křepel et al., 2014, Fuel cycle advantages and dynamics features of liquid fueled MSR, Ann. Nucl. Energy, volume 64, page 380-397.

[4] A. W. Harto, 2015, Sustainable criticality analysis of PCMSR fuel using thorium as a sustainable fuel and low enriched uranium as starting fuel, Int. J. Nucl. Energy Sci. Technol., volume 9, no. 3, page 224-237.

[5] A. W. Harto, 2018, Study on the Ability of PCMSR to Produce Valuable Isotopes as a ByProduct of Energy Generation, Indonesia. J. Phys. Nucl. Appl., volume 3, no. 1, page 714.

[6] G. C. Li et al., 2018, Optimization of Th-U fuel breeding based on a single-fluid doublezone thorium molten salt reactor, Prog. Nucl. Energy, volume 108, page 144-151.

[7] C. Y. Zou, C. Z. Cai, C. G. Yu, J. H. Wu, and J. G. Chen, 2018, Transition to thorium fuel cycle for TMSR, Nucl. Eng. Des., volume 330, page 420-428.

[8] J. Devanney, L. Jorgensen, J. Livingston, R. W. Moir, A. C. Rodenburg and C. Uhlik, 2015, ThorCon Executive Summary.

[9] H. G. MacPherson, 1985, Molten Salt Reactor Adventure, Nucl. Sci. Eng., volume 90, no. 4, page 374-380.

[10] A. Waris, I. K. Aji, S. Pramuditya, Novitrian, S. Permana, and Z. Su'ud, 2015, Comparative Studies on Plutonium and Minor Actinides Utilization in Small Molten Salt Reactors with Various Powers and Core Sizes, Energy Procedia, volume 71, page 62-68. 
[11] D. Heuer, E. Merle-Lucotte, M. Allibert, M. Brovchenko, V. Ghetta, and P. Rubiolo, 2014, Towards the thorium fuel cycle with molten salt fast reactors, Ann. Nucl. Energy, volume 64 , page 421-429.

[12] J. Zhou, J. Chen, J. Wu, S. Xia, and C. Zou, 2020, Influence of 7Li enrichment on Th-U fuel breeding performance for molten salt reactors under different neutron spectra, Prog. Nucl. Energy, volume 120, page 103213.

[13] C. Yu et al., 2017, Minor actinide incineration and Th-U breeding in a small FLiNaK Molten Salt Fast Reactor, Ann. Nucl. Energy, volume 99, page 335-344.

[14] V. Ignatiev et al., 2014, Molten salt actinide recycler and transforming system without and with Th-U support: Fuel cycle flexibility and key material properties, Ann. Nucl. Energy, volume 64, page 408-420.

[15] I. Scott, 2017, Stable salt fast reactor, in Molten Salt Reactors and Thorium Energy, volume 1, Elsevier Ltd, page 571-580.

[16] A. Huke, G. Ruprecht, D. Weißbach, S. Gottlieb, A. Hussein, and K. Czerski, 2015, The Dual Fluid Reactor - A novel concept for a fast nuclear reactor of high efficiency, Ann. Nucl. Energy, volume 80, page 225-235.

[17] Terra Power, Molten Chloride Fast Reactor Technology. [Online]. Available: https://www.terrapower.com/our-work/molten-chloride-fast-reactor-technology/. [Accessed: 08-Apr-2020].

[18] E. Industries, The Molten Chloride Salt Fast Reactor. [Online]. Available: http://www.elysiumindustries.com/technology. [Accessed: 08-Apr-2020].

[19] J. Smith and W. E. Simmons, 1974, An Assessment of a 2500 MWe Molten Chloride Salt Fast Reactor, Technical Report, Dorset, United Kingdom Atomic Energy Authority.

[20] J. Ligou, 1972, Molten Chlorides Fast Breeder Reactor: Reactor Physics Calculations, Wuerenlingen, Eidg. Institut fuer Reaktorforschung Wuerenlingen.

[21] A. Mourogov and P. M. Bokov, 2006, Potentialities of the fast spectrum molten salt reactor concept: REBUS-3700, Energy Convers. Manag., volume 47, no. 17, page 2761-2771.

[22] I. R. Scott, 2019, The Stable Salt Reactor-A Radically Simpler Option for Use of Molten Salt Fuel, in Thorium—Energy for the Future, Springer Singapore, page 445-453.

[23] L.-Y. He, G.-C. Li, S.-P. Xia, J.-G. Chen, Y. Zou, and G.-M. Liu, 2020, Effect of 37Cl enrichment on neutrons in a molten chloride salt fast reactor, Nucl. Sci. Tech., volume 31, no. 3, page 27.

[24] G. C. Li et al., 2018, Optimization of Th-U fuel breeding based on a single-fluid doublezone thorium molten salt reactor, Prog. Nucl. Energy, volume 108, page 144-151.

[25] T. M. Sembiring, J. Susilo, and S. Pinem, 2018, Evaluation of the AP1000 delayed neutron parameters using MCNP6, in Journal of Physics: Conference Series, volume 962, page 012030.

[26] M. Aufiero et al., 2014, Calculating the effective delayed neutron fraction in the Molten Salt Fast Reactor: Analytical, deterministic and Monte Carlo approaches, Ann. Nucl. Energy, volume 65, page 78-90. 
[27] V. Singh, M. R. Lish, O. Chvála, and B. R. Upadhyaya, 2017, Dynamics and control of molten-salt breeder reactor, Nucl. Eng. Technol., volume 49, no. 5, page 887-895.

[28] R. Yoshioka and M. Kinoshita, 2017, Liquid fuel, thermal neutron spectrum reactors, in Molten Salt Reactors and Thorium Energy, Elsevier Ltd, page 281-373. 